\title{
Plant Extract Loaded Nanoparticles
}

\section{Patihul Husni1,2, Zelika Mega Ramadhania ${ }^{3,4}$}

${ }^{1}$ Department of Pharmaceutics and Pharmaceutical Technology, Faculty of Pharmacy, Universitas Padjadjaran, Jatinangor 45363, Indonesia

${ }^{2}$ Department of Global Innovative Drugs, College of Pharmacy, Chung-Ang University, 221 Heukseok dong, Dongjak-gu, Seoul 06974, Korea

${ }^{3}$ Department of Pharmaceutical Biology, Faculty of Pharmacy, Universitas Padjadjaran, Jatinangor 45363, Indonesia

${ }^{4}$ Graduate School of Biotechnology, College of Life Sciences, Kyung Hee University, Yongin si, Gyeonggi do, 17104, Republic of Korea

Received: 12 March 2021, Revised: 8 April 2021, Accepted: 12 April 2021, Published: 17 April 2021

\begin{abstract}
Plant extract, a natural source containing complex mixture of compounds, offers many properties such as antiparasitic, antibiotic, antioxidant, anti-hypertensive, antiviral, insecticide, anticancer, antifungal, hypoglycemic properties. Recent research has been focused on developing formulation the plant extracts not only to deliver them safely but also to enhance its therapeutic efficacy. Nanotechnology-based strategies have been proposed as a system that can be used to formulate plant extracts. Plant extract loaded nanoparticles (NPs) is aimed to facilitate in crossing the biological barriers, to increase bioavailability of poorly water-soluble phytochemicals, to encapsulate mixture compounds of different phytochemicals, to provide targeted delivery of phytochemicals to specific organs resulting in low toxicity, to get effective purification process, to mask unpleasant taste and odor, to protect sensitive phytochemicals from biological (e.g. enzyme, $\mathrm{pH}$ ) and environmental (e.g. light, temperature, humidity) degradation, to control release of encapsulated phytochemicals, and to provide a more flexible control over the size and shape of the NPs. This review is focused on plant extract loaded NPs including its advantages, stages for developing formulation of plant extract loaded NPs, and nanosystem used to loading plant extract. In addition, this review also depicts studies which have been conducted by many researchers in developing plant extract loaded NPs. The data were collected from published journals with 21 and 39 journals as primary and supporting literatures, respectively. Plant extracts loaded NPs could be a promising delivery system for active phytochemical contained in the plant extract which is not only to deliver them safely but also to enhance its therapeutic efficacy.
\end{abstract}

Keywords: plant, extract, nanoparticle 


\section{Introduction}

Plants have been used for treatment various diseases since long time. Biological active compounds are obtained by extracting mainly the leaves, the fruits, the stems, or roots of medicinal plants (1). The biological active compounds can have antiparasitic, antibiotic, antioxidant, anti-hypertensive, antiviral, insecticide, anticancer, antifungal, hypoglycemic properties (1). To increase the application of plant extracts, a technology must be performed in formulation development of plant extracts (2).

Recently, many studies use nanotechnology to formulate plant extract. By using nanotechnology-based systems, biopharmaceutical and technological properties of plant extracts can be improved (2). The nanosystems used commonly are nanoparticles (NPs) (either polymer or lipid-based NPs), liposomes, and nanoemulsions (2). Formulation development of plant extract loaded NPs has been focused by researchers to combine the benefits offered by nanotechnology and the diversity of biological activities of plant extracts (2).

Plant extract loaded NPs offers numerous advantages because of their size and unique physicochemical characteristics. Moreover, plant extract loaded NPs can be used to decrease plant extracts toxicity, to provide targeted drug delivery and to solve stability related problems (1). There are several stages involved in developing preparation of plant extract loaded NPs (1).

The aim of this review is to describe about plant extract loaded NPs including its advantages, stages for developing formulation of plant extract loaded NPs, and nanosystem used to encapsulate plant extract. In addition, this review also shows many studies which have been investigated by researchers to develop plant extract loaded NPs.

\section{Methodology}

This review was obtained by using specific keywords "plant extract and nanoparticles," by following an inclusions criteria (related to specific keywords) and exclusions criteria (opinions and unrelated topics). We collected about 21 journals published in 2010-2021 as a primary literatures and 39 journals published as supporting literature. The flowchart of methodology can be seen in Figure 1.

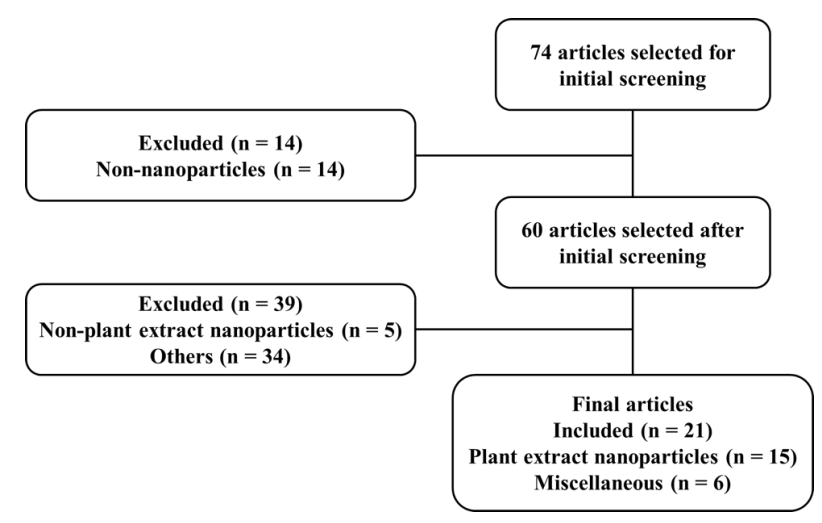

Figure 1. Flowchart of methodology

\section{Nanoparticles (NPs)}

The rapid development of nanotechnology has good prospect to develop formulation of active compounds loaded NPs. NPs are commonly defined to particulate substances which have diameter in the range of 1 to $100 \mathrm{~nm}$ although in principle NPs are described as substances with length of $1-1000 \mathrm{~nm}$ in at least one dimension (3-6). NPs have been widely used in many applications such as medications, electronics, manufacturing and materials, environment, mechanical industries, etc. (6). Classification of NPs are polymeric NPs, lipidbased NPs, carbon-based NPs, ceramics NPs, semiconductor NPs, and metal NPs and can be synthesized either top-down or bottom-up method (6). The most common nanoparticle systems used for the delivery of natural products are nanoliposome, polymeric NPs, solid lipid nanoparticle (SLN), dendrimer, nanocrystal, nanoemulsion, micelle, hydrogel, fullerene, and zeolite (7). 
In addition, nanotechnology-based systems can be also used to improve biopharmaceutical and technological properties of plant extracts (2). Plant extract loaded NPs can be used for cosmetic, food additives, and phytotheraphy (e.g. antioxidant, antiviral, hepatoprotection, antidiabetic, anti-inflammatory, anticholesterolemia, antiulcerolitic, anticancer activity) applications $(1,2)$.

The nanosystems used commonly are nanoparticles (NPs) (either polymer or lipidbased NPs), liposomes, and nanoemulsions (2). Figure 2 shows the nanosystem used for loading plant extracts. Some techniques which are very frequently used for loading plant extract into NPs are emulsion solvent evaporation, nanoprecipitation, emulsion solvent diffusion, and ionic gelation. These techniques differ by their principles and are also influenced by nature of the encapsulated phytochemicals. Correct selection of the techniques very important to obtain a formulation of plant extract loaded NPs (1).

\section{Advantages and disadvantages of plant extract loaded nanoparticle}

Many studies reveal that nanotechnology offers many benefits, including for formulation of plant extract loaded NPs. Plant extract loaded nanoparticle have several advantages such as facilitating in crossing the biological barriers, increasing bioavailability of poorly watersoluble phytochemicals, encapsulation of mixture compounds of different phytochemicals, providing targeted delivery of phytochemicals to specific organs resulting in reducing toxicity of phytochemicals, getting effective purification process, masking unpleasant taste and odor, increasing stability of the encapsulated phytochemicals by protection of the sensitive phytochemicals from biological (e.g. enzyme, pH) and environmental (e.g. light, temperature, humidity) degradation or inactivation, controlling the release of encapsulated phytochemicals, and providing a more flexible control over the size and shape of the NPs during synthesis of NPs using plant extract (1, 7-12).

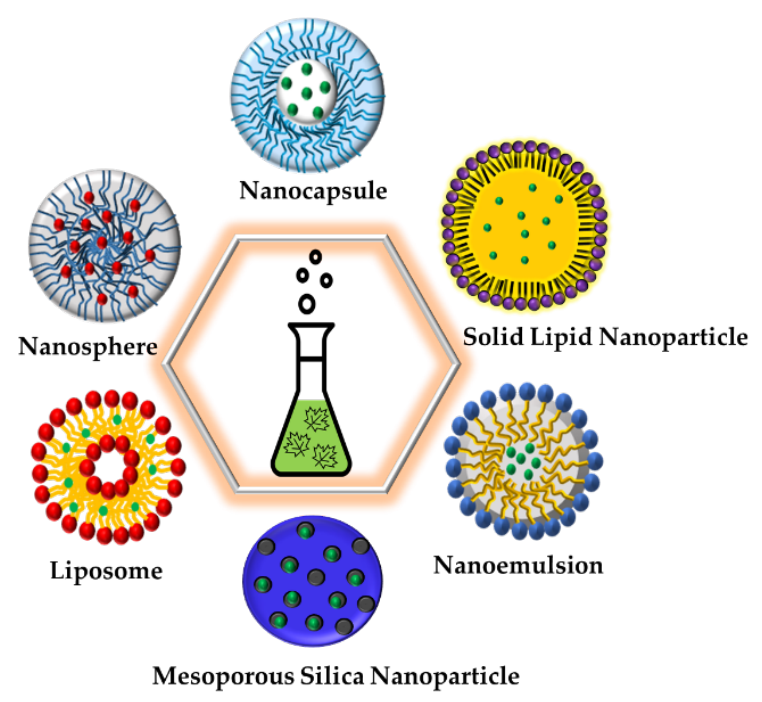

Figure 2. Illustration of nanosystems used for loading plant extract

On the other hand, the drawback of NPs should be a careful consideration in formulation of plant extract loaded NPs such as a tendency to high aggregation in biological system due to high surface area and energy, high immunogenicity, long and expensive cost, and chance of poor targeting (13).

\section{Stages for developing preparation of plant extract loaded nanoparticle}

Encapsulation of plant extract into NPs can be used to overcome problems such as toxicity risks and extract instability (1). Studies on formulations containing plant extract loaded NPs generally reports about standardizing techniques for NPs formulation, physicochemical characterization of the NPs (size, zeta potential, morphology, etc.), encapsulation/loading efficiency of the active component in the NPs, the release profiles of the active component from the NPs, in vitro and in vivo evaluations both free extract and embedded extract and stability studies of the formulation (1).

For example, Kamel et al. encapsulated both extracts of Cinnamomum cassia and Origanum 
vulgare in solid lipid nanoparticles (SLN) and coated the SLN with chitosan (SLN-Cs) to encapsulate cinnamon and oregano extract, minimize opsonization, and facilitate passivetargeting. This group demonstrated the success of the suggested combination with 5fluorouracil for treating human colon carcinoma with a low dose leading to decreasing side effects and allowing uninterrupted therapy. Three phases were applied to develop the SLN-Cs (Figure 3). Phase one was focused on extract standardization. Phase two was aimed to encapsulate both extracts in SLN-Cs to obtain an optimum formulation of SLN-Cs. Phase three was concerned on the cytotoxicity evaluation (14).

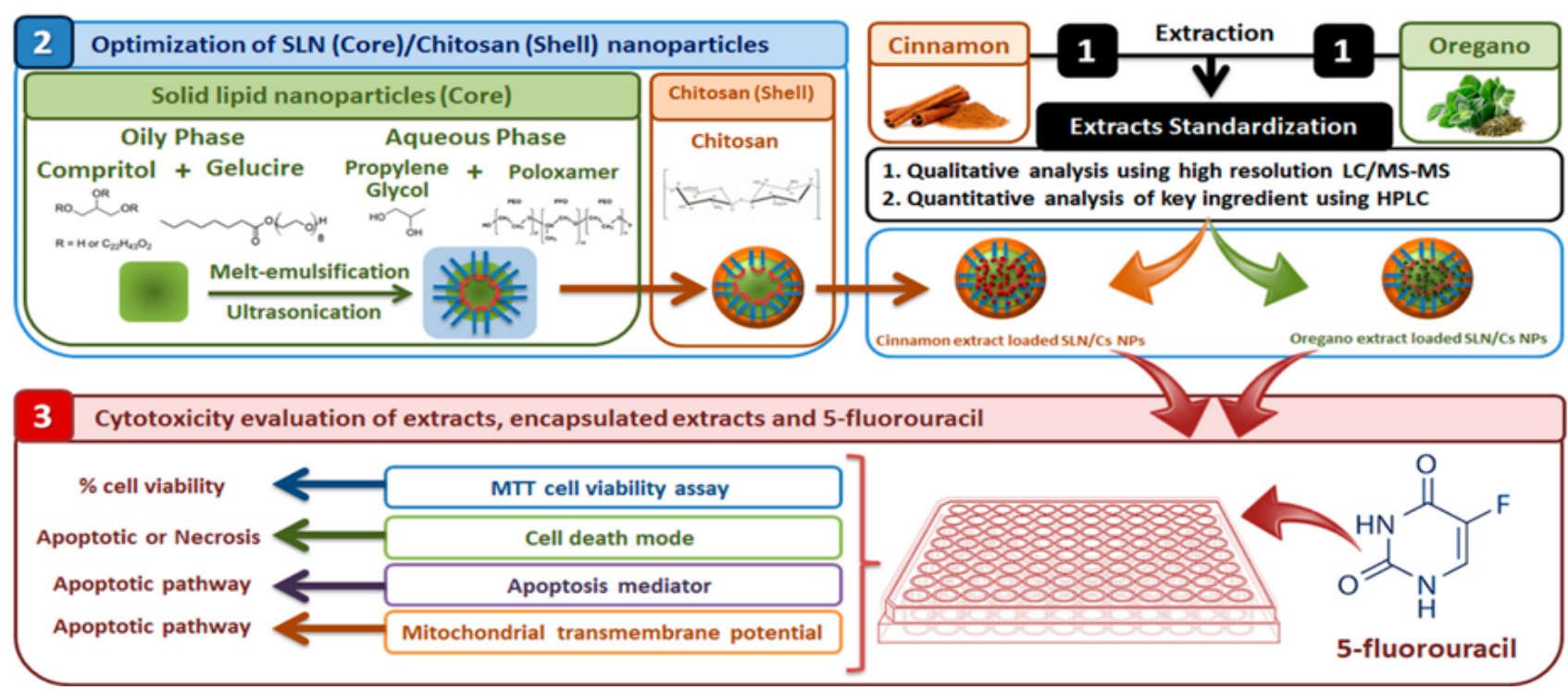

Figure 3. Schematic illustration of the different phases of the study. Reproduced with permission of Kamel KM, Khalil IA, Rateb ME, Elgendy H, Elhawary S., Chitosan-Coated Cinnamon/OreganoLoaded Solid Lipid Nanoparticles to Augment 5-Fluorouracil Cytotoxicity for Colorectal Cancer: Extract Standardization, Nanoparticle Optimization, and Cytotoxicity Evaluation; published by American Chemical Society, 2017.

Development of plant extract loaded NPs formulation generally have the following stages as depicted in Figure 4. The following stages are summarized from several published studies $(1,2,7,14)$.

\section{Nanoparticle loading plant extract}

Currently, researchers are interested to develop formulations of plant extract loaded NPs (1). Studies about plant extract loaded nanoparticles formulation are showed in Table 1. According to Table 1, nanoparticle systems used to formulate plant extract are polymeric NPs, nanoliposome, solid lipid nanoparticle (SLN), silica NPs, etc. polymeric-based nanoparticle is the most used as a nanosystem to load the plant extract. In addition, poly (lactic-co-glycolic) acid (PLGA) is the most used polymer to construct plant extract loaded NPs. Other nanosystems use poly-lactic acid (PLA), xanthan gum-shellac, polyvinyl pyrrolidine (PVP), ethyl cellulose (EC), methyl cellulose (MC), poly(epsilon-caprolactone) (PCL), hydroxypropyl-methylcellulose (HPMC), chitosan, gelatin, hyaluronic acid (HA), etc. for preparing the NPs.

Encapsulation of plant extract can be used for either imaging or therapeutic application. Liu and co-workers prepared turmeric extract encapsulated by PLGA for bioimaging and 
Table 1. Studies about formulation of plant extract loaded NPs

\begin{tabular}{|c|c|c|}
\hline Extract name & System & Reference \\
\hline $\begin{array}{l}\text { Cinnamomum cassia and } \\
\text { Origanum vulgare }\end{array}$ & SLN coated with chitosan & (14) \\
\hline Gelsemium sempervirens & PLGA NPs & (15) \\
\hline Polygala senega & PLGA NPs & (16) \\
\hline \multirow{3}{*}{ Vitis $s p$} & PLGA NPs & (17) \\
\hline & PLA NPs & $(18)$ \\
\hline & PLGA NPs & (19) \\
\hline Phytolacca decandra & PLGA NPs & $(20)$ \\
\hline Syzygium jambolanum & PLGA NPs & $(21)$ \\
\hline \multirow{2}{*}{ Cinnamomum spp } & PLGA NPs & $(22)$ \\
\hline & Xanthan gum-shellac NPs & $(23)$ \\
\hline Emblica officinalis & PVP NPs & $(24)$ \\
\hline \multirow{2}{*}{ Garcinia mangostana } & EC NPs & $(25)$ \\
\hline & EC and MC NPs & $(26)$ \\
\hline Passiflora serratodigitata L. & PCL NPs & $(27)$ \\
\hline Lavandula spp & PLGA NPs & $(28)$ \\
\hline Picrorhiza kurroa & $\begin{array}{c}\text { PLA and Pluronic-F-68 } \\
\text { (polyoxyethylene-polyoxypropylene } \\
\text { block copolymer) NPs }\end{array}$ & (29) \\
\hline Uncaria tomentosa & PLGA NPs & $(30)$ \\
\hline Carum copticum & $\begin{array}{l}\mathrm{MnFe}_{2} \mathrm{O} 4 \text { NPs coated with PEGylated } \\
\text { chitosan }\end{array}$ & $(31)$ \\
\hline Malus domestica & Silver NPs & $(32)$ \\
\hline Elettaria car damomum Maton & Gelatin NPs & (33) \\
\hline Camellia sinensis & HPMC containing PLA NPs & $(34)$ \\
\hline Houttuynia cordata & $\begin{array}{l}\text { Solid lipid NPs (SLNs) using Stearic } \\
\text { acid (SA) and Poloxamer 188 } \\
\text { (P188) or poloxamer } 407 \text { (P407) }\end{array}$ & (35) \\
\hline Ilex paraguariensis & PCL or PLGA NPs & $(36)$ \\
\hline Annona squamosa & Chitosan NPs & $(37)$ \\
\hline Beta vulgaris & PEGylated gelatin NPs & $(38)$ \\
\hline Centella asiatica & $\begin{array}{c}\text { Lipid NPs consisting of stearic acid, } \\
\text { oleic acid, lecithin, and sodium } \\
\text { taurodeoxycholate }\end{array}$ & (39) \\
\hline \multirow{3}{*}{ Curcuma longa } & $\begin{array}{c}\text { Nanoliposomes consisting of } \\
\text { phosphatidylcholine }\end{array}$ & $(40)$ \\
\hline & Mesoporous silica NPs & $(41)$ \\
\hline & PLGA NPs & $(42)$ \\
\hline Dendropanax morbifera & $\begin{array}{l}\text { HA or O-carboxymethyl chitosan } \\
\text { (CMC)- } \\
\text { stabilized zinc oxide nanocomposites } \\
\text { (ZnONcs) }\end{array}$ & (43) \\
\hline Allium sativum & $\begin{array}{l}\text { Solgel NPs consisting of } \\
\text { tetramethylorthosilicate }\end{array}$ & (44) \\
\hline Glycyrrhiza glabra & $\begin{array}{l}\text { Liposomes consisting of soyabean } \\
\text { phosphatidylcholine and cholesterol }\end{array}$ & $(45)$ \\
\hline Hibiscus sabdariffa & $\begin{array}{c}\text { Nanostructured lipid } \\
\text { carriers (NLC) composed of solid } \\
\text { lipid (Biograpress } \\
\text { ATO Vegetal BM } 297 \\
\text { and lipid liquid (Soybean oil) }\end{array}$ & (46) \\
\hline
\end{tabular}




\begin{tabular}{ccc}
\hline Hypericum Perforatum L. & PLGA NPs & $(47)$ \\
\hline Lamium album & Porous hollow silica NPs & $(48)$ \\
\hline Solanum lycocarpum & $\begin{array}{c}\text { Natural lipid-based NPs composed of } \\
\text { myristyl myristate }\end{array}$ & $(49)$ \\
\hline Camellia sinensis & PCL NPs & $(50)$ \\
\hline Punica granatum & $\begin{array}{c}\text { SLN using precirol or stearic acid, } \\
\text { lecithin, and tween 80 or poloxamer 188 }\end{array}$ & $(51)$ \\
\hline Gynostemma pentaphyllum & Zinc Oxide NPs & $(52)$ \\
\hline Cordyceps militaris & Nanoemulsion & $(53)$ \\
\hline Amomum longligulare & Zinc Oxide NPs & $(54)$ \\
\hline Scutellaria baicalensis & Zinc Oxide NPs & $(55)$ \\
\hline Hippophae rhamnoides & Gold and Silver NPs & $(56)$ \\
\hline Stevia rebaudiana & Zinc Oxide NPs & $(57)$ \\
\hline Suaeda japonica & Zinc Oxide NPs & $(58)$ \\
\hline Crataegus pinnatifida & Zinc Oxide NPs & $(59)$ \\
\hline
\end{tabular}

antimicrobial applications. Curcumin is the main content in the rhizome of the turmeric. This group proved that Curcumin loaded PLGA NPs (Cur-PLGA NPs) are successfully to be used for not only bioimaging but also antibacterial application (Figure 5) (42).

The release of loaded phytochemicals can be controlled and the stability can be increased when plant extract is loaded in NPs. Sanna et al. showed the effectiveness of white tea extract loaded PCL NPs. This nutraceutical application is used to control the release of tea polyphenols and to maintain the antioxidant activity. The release study showed that the polyphenols was released from NPs about $20 \%$ at $\mathrm{pH} 1.2$ (simulated gastric medium) and $80 \%$ at $\mathrm{pH} 7.4$, respectively (Figure 6). This result proved that NPs can be used to control delivery of the polyphenols In addition, the encapsulation of the white tea extract into NPs significantly increased stability, thus preventing the losses of TPC and catechins over 30 days of storage (50). In another study, Kim et al. developed Houttuynia cordata extract-loaded solid lipid NPs (H-SLNs) for oral delivery. This group reported that $92.9-95.9 \%$ of quercitrin encapsulated into SLNs. Interestingly, sustained release of quercitrin from $H$. cordata extracts was provided by H-SLNs (35).

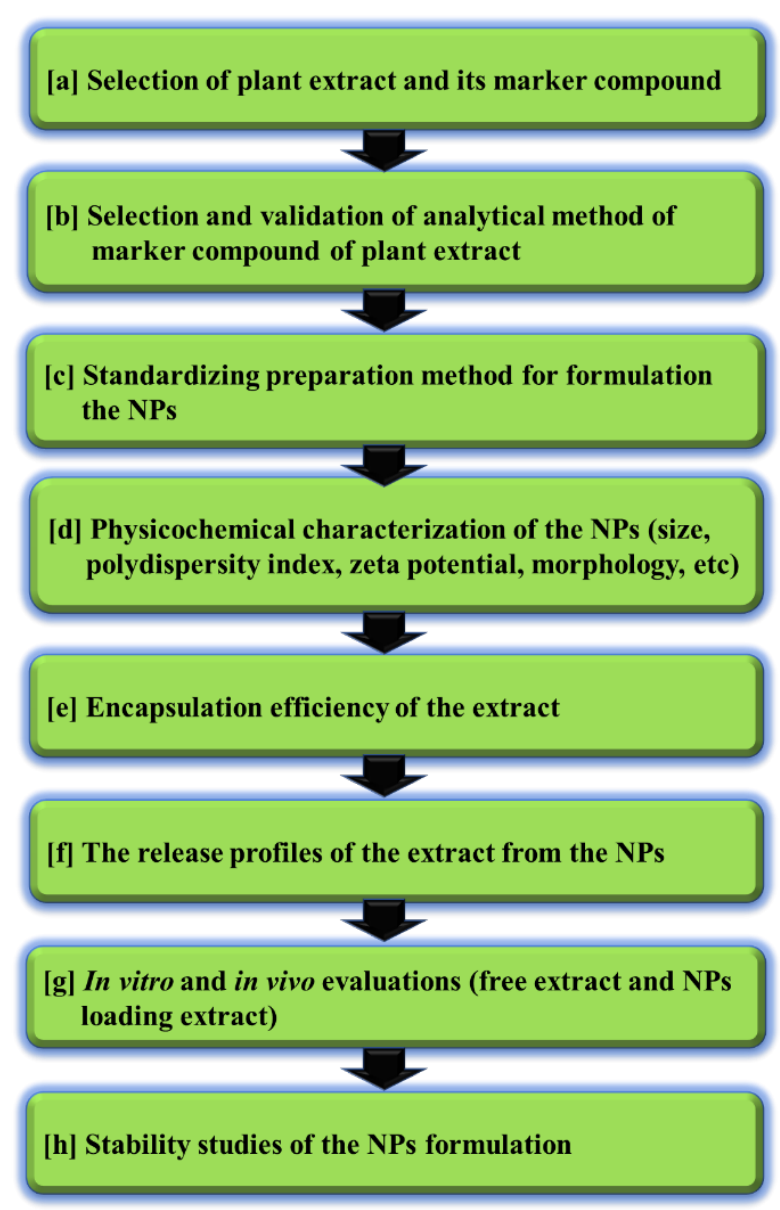

Figure 4. Schematic illustration of stages for developing preparation of plant extract loaded NPs.

In case of the use of plant extract loaded NPs in phytotheraphy applications, Paul et al. prepared root extract of Polygala senega encapsulated 

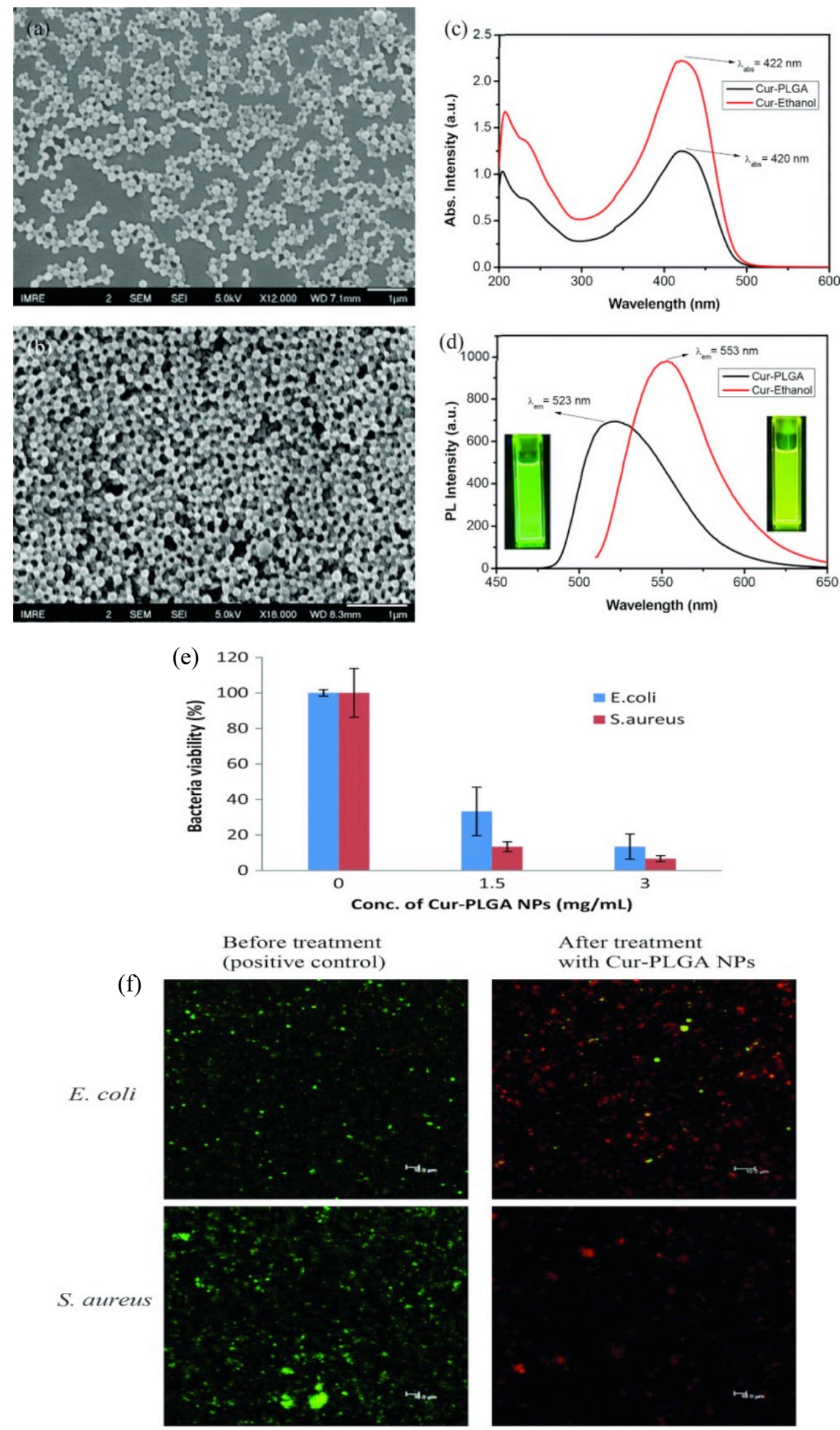

Figure 5. a) SEM image of Cur-PLGA NPs with lower magnification, b) SEM image of Cur-PLGA NPs with high magnification, c) absorption spectra of Cur-PLGA NPs and curcumin solution in ethanol, d) fluorescent spectra of Cur-PLGA NPs and curcumin solution in ethanol, e) Antimicrobial effect of Cur-PLGA NPs against E. coli and $S$. aureus bacterial cells. f) Confocal microscopy images showing the antimicrobial effect of Cur-PLGA NPs on E. coli and $S$. aureus. Positive controls are bacteria that are not treated with Cur-PLGA NPs. Live bacteria are stained green. Reproduced with permission of Liu M, Teng CP, Win KY, Chen Y, Zhang X, Yang DP, et al., Polymeric Encapsulation of Turmeric Extract for Bioimaging and Antimicrobial Applications; published by John Wiley and Sons, 2019. 
PLGA as an anticancer. This group reported that the anticancer activity of the extract loaded PLGA NPs was more effective than extract per se (16). In addition to anticancer activity, PanIn et al. formulated Garcinia mangostana extract-encapsulated EC and a polymer blend of EC and MC NPs. The NPs loading extract successfully improved the bioavailability of Garcinia mangostana extract, enhanced cellular uptake, and showed effective anticancer activity (25). In another studies, Strasser et al. constructed nanoencapsulated Passiflora serratodigitata $L$. extracts as an antiulcerogenic activity (27). Other than that in phytotherapy applications, Jia et al. developed nanoencapsulation of Picrorhiza kurroa extract as food supplement with hepatoprotective activity (29). Recently, plant extract loaded NPs could be interesting field for research in many areas, such as health, food, cosmetics, medicine, environment, etc.

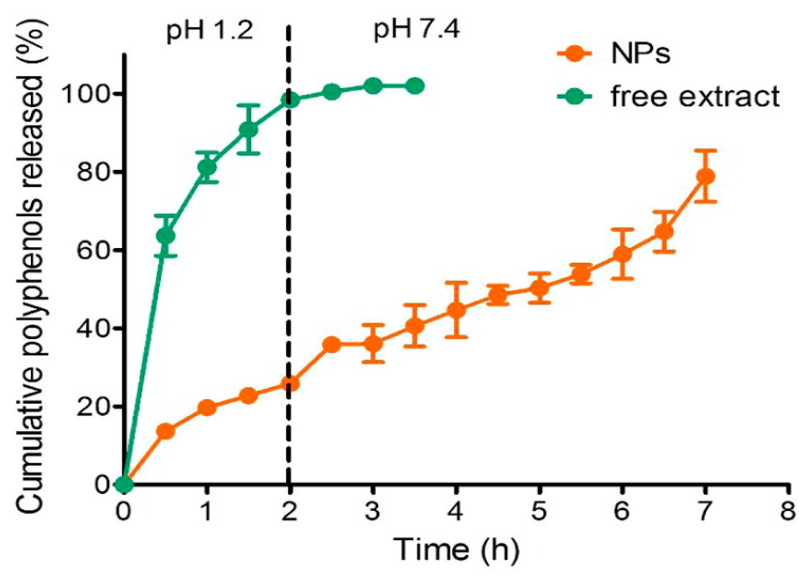

Figure 6. In vitro release profiles of polyphenols (TPC) from free white tea extract and from tea extract-loaded NPs in $0.1 \mathrm{M} \mathrm{HCl}$ (pH 1.2) for $2 \mathrm{~h}$, followed by PBS ( $\mathrm{pH} 7.4$ ) for $5 \mathrm{~h}$. Data are means $\pm \mathrm{SD}, \mathrm{n}=3$. Reproduced with permission of Sanna V, Lubinu G, Madau P, Pala N, Nurra S, Mariani A, et al., Polymeric nanoparticles encapsulating white tea extract for nutraceutical application; published by American Chemical Society, 2015.

\section{Conclusion}

The use of nanotechnology-based systems has been grown rapidly. Plant extract loaded nanosystems such as nanoparticles (NPs) (either polymer or lipid-based NPs), liposomes, and nanoemulsions can bring many benefits which can be aimed to facilitate in crossing the biological barriers, to increase bioavailabilityof poorly water-soluble phytochemicals, to encapsulate mixture compounds of different phytochemicals, to provide targeted delivery of phytochemicals to specific organs resulting in low toxicity, to get effective purification process, to mask unpleasant taste and odor, to protect sensitive phytochemicals from biological (e.g. enzyme, pH) and environmental (e.g. light, temperature, humidity) degradation, to control release of encapsulated phytochemicals, and to provide a more flexible control over the size and shape of the NPs. Recent research has been focused on developing formulation the plant extracts not only to deliver them safely but also to enhance its therapeutic efficacy which involves several stages for developing formulation of plant extract loaded NPs.

\section{References}

1. Armendariz-Barragan B, Zafar N, Badri W, Galindo-Rodriguez SA, Kabbaj D, Fessi H, et al. Plant extracts: from encapsulation to application. Expert Opin Drug Deliv. 2016;13(8):1165-75.

2. Zorzi GK, Carvalho ELS, von Poser GL, Teixeira HF. On the use of nanotechnology-based strategies for association of complex matrices from plant extracts. Rev Bras Farmacogn. 2015;25(4):426-36.

3. Khan I, Saeed K, Khan I. Nanoparticles: Properties, applications and toxicities. Arab J Chem. 2019;12(7):908-31.

4. Jeevanandam J, Barhoum A, Chan YS, Dufresne A, Danquah MK. Review on nanoparticles and nanostructured materials: history, sources, toxicity and regulations. Beilstein J Nanotechnol. 2018;9:1050-74. 
5. Bobo D, Robinson KJ, Islam J, Thurecht KJ, Corrie SR. Nanoparticle-Based Medicines: A Review of FDA-Approved Materials and Clinical Trials to Date. Pharm Res. 2016;33(10):2373-87.

6. Heera P, Shanmugam S. Nanoparticle characterization and application: an overview. Int J Curr Microbiol App Sci. 2015;4(8):37986.

7. Shakeri A, Sahebkar A. Opinion Paper: Nanotechnology: A Successful Approach to Improve Oral Bioavailability of Phytochemicals. Recent Pat Drug Deliv Formul. 2016;10(1):4-6.

8. Brambilla D, Luciani P, Leroux JC. Breakthrough discoveries in drug delivery technologies: the next 30 years. J Control Release. 2014;190:9-14.

9. Makarov VV, Love AJ, Sinitsyna OV, Makarova SS, Yaminsky IV, Taliansky ME, et al. "Green" Nanotechnologies: Synthesis of Metal Nanoparticles Using Plants. Acta Naturae. 2014;6(1):35-44.

10. Chatterjee A, Kwatra N, Abraham J. Nanoparticles fabrication by plant extracts. Phytonanotechnology; Elsevier: Amsterdam, The Netherlands. 2020:143-57.

11. Bilia AR, Piazzini V, Asprea M, Risaliti L, Vanti G, Bergonzi MC. Plants Extracts Loaded in Nanocarriers: an Emergent Formulating Approach. Nat Prod Commun. 2018;13(9):1157-60.

12. Moradi SZ, Momtaz S, Bayrami Z, Farzaei MH, Abdollahi M. Nanoformulations of Herbal Extracts in Treatment of Neurodegenerative Disorders. Front Bioeng Biotechnol. 2020;8:238.

13. Mamillapalli V, Atmakuri AM, Khantamneni P. Nanoparticles for Herbal Extracts. Asian J Pharm. 2016;10(2):S54-S60.

14. Kamel KM, Khalil IA, Rateb ME, Elgendy $\mathrm{H}$, Elhawary S. Chitosan-Coated
Cinnamon/Oregano-Loaded Solid Lipid Nanoparticles to Augment 5-Fluorouracil Cytotoxicity for Colorectal Cancer: Extract Standardization, Nanoparticle Optimization, and Cytotoxicity Evaluation. J Agric Food Chem. 2017;65(36):7966-81.

15. Bhattacharyya SS, Paul S, KhudaBukhsh AR. Encapsulated plant extract (Gelsemium sempervirens) poly (lactide-coglycolide) nanoparticles enhance cellular uptake and increase bioactivity in vitro. Exp Biol Med. 2010;235(6):678-88.

16. Paul S, Bhattacharyya SS, Boujedaini N, Khuda-Bukhsh AR. Anticancer Potentials of Root Extract of Polygala senega and Its PLGA Nanoparticles-Encapsulated Form. Evid Based Complement Alternat Med. 2011;2011.

17. Narayanan S, Binulal NS, Mony U, Manzoor K, Nair S, Menon D. Folate targeted polymeric 'green' nanotherapy for cancer. Nanotechnology. 2010;21(28):285107.

18. Fernandez K, Aburto J, von Plessing C, Rockel M, Aspe E. Factorial design optimization and characterization of poly-lactic acid (PLA) nanoparticle formation for the delivery of grape extracts. Food Chem. 2016;207:75-85.

19. Simonetti G, Palocci C, Valletta A, Kolesova O, Chronopoulou L, Donati L, et al. Anti-Candida Biofilm Activity of Pterostilbene or Crude Extract from Non-Fermented Grape Pomace Entrapped in Biopolymeric Nanoparticles. Molecules. 2019;24(11).

20. Das J, Das S, Samadder A, Bhadra K, Khuda-Bukhsh AR. Poly (lactide-co-glycolide) encapsulated extract of Phytolacca decandra demonstrates better intervention against induced lung adenocarcinoma in mice and on A549 cells. Eur J Pharm Sci. 2012;47(2):31324.

21. Samadder A, Das S, Das J, Paul A, Khuda-Bukhsh AR. Ameliorative effects of Syzygium jambolanum extract and its poly 
(lactic-co-glycolic) acid nano-encapsulated form on arsenic-induced hyperglycemic stress: a multi-parametric evaluation. J Acupunct Meridian Stud. 2012;5(6):310-8.

22. Hill LE, Taylor TM, Gomes C. Antimicrobial efficacy of poly (DL-lactide-coglycolide) (PLGA) nanoparticles with entrapped cinnamon bark extract against Listeria monocytogenes and Salmonella typhimurium. J Food Sci. 2013;78(4):N626-32.

23. Muhammad DRA, Doost AS, Gupta V, bin Sintang MD, Van de Walle D, Van der Meeren P, et al. Stability and functionality of xanthan gum-shellac nanoparticles for the encapsulation of cinnamon bark extract. Food Hydrocolloid. 2020;100.

24. Renuka R, Sandhya P, Hari BV, Devi DR. Design of polymeric nanoparticles of emblica officinalis extracts and study of in vitro therapeutic effects. Current Trends in Biotechnology and Pharmacy. 2013;7(3):71624.

25. Pan-In P, Wanichwecharungruang S, Hanes J, Kim AJ. Cellular trafficking and anticancer activity of Garcinia mangostana extract-encapsulated polymeric nanoparticles. Int J Nanomedicine. 2014;9:3677-86.

26. Tachaprutinun A, Meinke MC, Richter H, Pan-In P, Wanichwecharungruang S, Knorr F, et al. Comparison of the skin penetration of Garcinia mangostana extract in particulate and non-particulate form. Eur J Pharm Biopharm. 2014;86(2):307-13.

27. Strasser M, Noriega P, Lobenberg R, Bou-Chacra N, Bacchi EM. Antiulcerogenic potential activity of free and nanoencapsulated Passiflora serratodigitata L. extracts. Biomed Res Int. 2014;2014:434067.

28. Pereira F, Baptista R, Ladeiras D, Madureira AM, Teixeira G, Rosado C, et al. Production and characterization of nanoparticles containing methanol extracts of
Portuguese Lavenders. Measurement. 2015;74:170-7.

29. Jia DW, Barwal I, Thakur S, Yadav SC. Methodology to nanoencapsulate hepatoprotective components from Picrorhiza kurroa as food supplement. Food Biosci. 2015;9:28-35.

30. Ribeiro AF, Ferreira CTG, dos Santos JF, Cabral LM, de Sousa VP. Design of experiments for the development of poly(D,Llactide-co-glycolide) nanoparticles loaded with Uncaria tomentosa. J Nanopart Res. 2015;17(2).

31. Esmaeili A, Ghobadianpour S. Antibacterial activity of Carum copticum extract loaded $\mathrm{MnFe} 2 \mathrm{O} 4$ nanoparticles coated with PEGylated chitosan. Ind Crop Prod. 2016;91:44-8.

32. Nagaich U, Gulati N, Chauhan S. Antioxidant and Antibacterial Potential of Silver Nanoparticles: Biogenic Synthesis Utilizing Apple Extract. J Pharm (Cairo). 2016;2016:7141523.

33. Nejat H, Rabiee M, Varshochian R, Tahriri M, Jazayeri HE, Rajadas J, et al. Preparation and characterization of cardamom extract-loaded gelatin nanoparticles as effective targeted drug delivery system to treat glioblastoma. React Funct Polym. 2017;120:46-56.

34. Wrona M, Cran MJ, Nerin C, Bigger SW. Development and characterisation of HPMC films containing PLA nanoparticles loaded with green tea extract for food packaging applications. Carbohyd Polym. 2017;156:108-17.

35. Kim JH, Baek JS, Park JK, Lee BJ, Kim MS, Hwang SJ, et al. Development of Houttuynia cordata Extract-Loaded Solid Lipid Nanoparticles for Oral Delivery: High Drug Loading Efficiency and Controlled Release. Molecules. 2017;22(12). 
36. dos Santos LP, Caon T, Battisti MA, da Silva CHB, Simoes CMO, Reginatto FH, et al. Antioxidant polymeric nanoparticles containing standardized extract of Ilex paraguariensis A. St.-Hil. for topical use. Ind Crop Prod. 2017;108:738-47.

37. Fadholly A, Proboningrat A, Iskandar RPD, Rantam FA, Sudjarwo SA. In vitro anticancer activity Annona squamosa extract nanoparticle on WiDr cells. J Adv Pharm Technol. 2019;10(4):149-54.

38. Amjadi S, Hamishehkar H, Ghorbani M. A novel smart PEGylated gelatin nanoparticle for co-delivery of doxorubicin and betanin: A strategy for enhancing the therapeutic efficacy of chemotherapy. Mat Sci Eng C-Mater. 2019;97:833-41.

39. da Rocha PBR, Souza BD, Andrade LM, dos Anjos JLV, Mendanha SA, Alonso A, et al. Enhanced asiaticoside skin permeation by Centella asiatica-loaded lipid nanoparticles: Effects of extract type and study of stratum corneum lipid dynamics. J Drug Deliv Sci Tec. 2019;50:305-12.

40. Karimi N, Ghanbarzadeh B, Hajibonabi F, Hojabri Z, Ganbarov K, Kafil HS, et al. Turmeric extract loaded nanoliposome as a potential antioxidant and antimicrobial nanocarrier for food applications. Food Biosci. 2019;29:110-7.

41. Erwin F, Novita BD, Prawesti GN. Analysis Of Antibacterial Effect Of Curcuminoid With Mesoporous Silica Nanoparticles On Staphylococcus Epidermidis. JOURNAL OF WIDYA MEDIKA JUNIOR. 2019;1(2):71-9.

42. Liu M, Teng CP, Win KY, Chen Y, Zhang X, Yang DP, et al. Polymeric Encapsulation of Turmeric Extract for Bioimaging and Antimicrobial Applications. Macromol Rapid Commun. 2019;40(5):e1800216.
43. Markus J, Mathiyalagan R, Kim YJ, Han $Y$, Jimenez-Perez ZE, Veronika $S$, et al. Synthesis of hyaluronic acid or Ocarboxymethyl chitosan-stabilized ZnOginsenoside $\mathrm{Rh} 2$ nanocomposites incorporated with aqueous leaf extract of Dendropanax morbifera Leveille: in vitro studies as potential sunscreen agents. New J Chem. 2019;43(23):9188-200.

44. Girish VM, Liang H, Aguilan JT, Nosanchuk JD, Friedman JM, Nacharaju P. Anti-biofilm activity of garlic extract loaded nanoparticles.

Nanomedicine.

2019;20:102009.

45. Viswanathan V, Pharande R, Bannalikar A, Gupta P, Gupta U, Mukne A. Inhalable liposomes of Glycyrrhiza glabra extract for use in tuberculosis: formulation, in vitro characterization, in vivo lung deposition, and in vivo pharmacodynamic studies. Drug Dev Ind Pharm. 2019;45(1):11-20.

46. Pimentel-Moral S, Teixeira C, Fernandes R, Borras-Linares I, Arraez-Roman D, Martinez-Ferez A, et al. Polyphenolsenriched Hibiscus sabdariffa extract-loaded nanostructured lipid carriers (NLC): Optimization by multi-response surface methodology. J Drug Deliv Sci Tec. 2019;49:660-7.

47. Amjadi I, Mohajeri M, Borisov A, Hosseini MS. Antiproliferative Effects of Free and Encapsulated Hypericum Perforatum L. Extract and Its Potential Interaction with Doxorubicin for Esophageal Squamous Cell Carcinoma. J Pharmacopuncture. 2019;22(2):102-8.

48. Esmaeili A, Pourkhodabakhshi F. Loading Metformin/Nettle Extract Lamium album L. subsp. Crinitum in Porous Hollow Silica Nanoparticle Coated by the Layer-byLayer Method. Silicon-Neth. 2020;12(3):52134. 
49. Carvalho IPS, Miranda MA, Silva LB, Chrysostomo-Massaro TN, Paschoal JAR, Bastos JK, et al. IN VITRO Anticancer Activity and Physicochemical Properties of SOLANUM LYCOCARPUM Alkaloidic Extract Loaded in Natural Lipid-Based Nanoparticles. Colloid Interfac Sci. 2019;28:5-14.

50. Sanna V, Lubinu G, Madau P, Pala N, Nurra S, Mariani A, et al. Polymeric nanoparticles encapsulating white tea extract for nutraceutical application. J Agric Food Chem. 2015;63(7):2026-32.

51. Badawi N, El-Say K, Attia D, ElNabarawi M, Elmazar M, Teaima $M$. Development of Pomegranate Extract-Loaded Solid Lipid Nanoparticles: Quality by Design Approach to Screen the Variables Affecting the Quality Attributes and Characterization. ACS Omega. 2020;5(34):21712-21.

52. Park JK, Rupa EJ, Arif MH, Li JF, Anandapadmanaban G, Kang JP, et al. Synthesis of zinc oxide nanoparticles from Gynostemma pentaphyllum extracts and assessment of photocatalytic properties through malachite green dye decolorization under UV illumination-A green approach. Optik. 2021;239:166249.

53. Rupa EJ, Li JF, Arif MH, Yaxi H, Puja AM, Chan AJ, et al. Cordyceps militaris Fungus Extracts-Mediated Nanoemulsion for Improvement Antioxidant, Antimicrobial, and Anti-Inflammatory Activities. Molecules. 2020;25(23).

54. Li JF, Rupa EJ, Hurh J, Huo Y, Chen L, Han Y, et al. Cordyceps militaris fungus mediated Zinc Oxide nanoparticles for the photocatalytic degradation of Methylene blue dye. Optik. 2019;183:691-7.
55. Liu YC, Li JF, Ahn J, Pu J, Rupa EJ, Huo $Y$, et al. Biosynthesis of zinc oxide nanoparticles by one-pot green synthesis using fruit extract of Amomum longiligulare and its activity as a photocatalyst. Optik. 2020;218.

56. Chen L, Huo Y, Han YX, Li JF, Ali H, Batjikh I, et al. Biosynthesis of gold and silver nanoparticles from Scutellaria baicalensis roots and in vitro applications. Appl Phys a-Mater. 2020;126(6).

57. Rupa EJ, Kaliraj L, Abid S, Yang DC, Jung SK. Synthesis of a Zinc Oxide Nanoflower Photocatalyst from Sea Buckthorn Fruit for Degradation of Industrial Dyes in Wastewater Treatment. Nanomaterials (Basel). 2019;9(12).

58. Seo KH, Markus J, Soshnikova V, Oh $\mathrm{KH}$, Anandapadmanaban G, Perez ZEJ, et al. Facile and green synthesis of zinc oxide particles by Stevia Rebaudiana and its in vitro photocatalytic activity. Inorg Nano-Met Chem. 2019;49(1):1-6.

59. Shim YJ, Soshnikova V, Anandapadmanaban G, Mathiyalagan R, Perez ZEJ, Markus J, et al. Zinc oxide nanoparticles synthesized by Suaeda japonica Makino and their photocatalytic degradation of methylene blue. Optik. 2019;182:1015-20.

60. Kang JP, Kim YJ, Singh P, Huo Y, Soshnikova V, Markus J, et al. Biosynthesis of gold and silver chloride nanoparticles mediated by Crataegus pinnatifida fruit extract: in vitro study of anti-inflammatory activities. Artif Cells Nanomed Biotechnol. 2018;46(8):153040. 